\title{
Eliminating or blocking 12/15-lipoxygenase reduces neutrophil recruitment in mouse models of acute lung injury
}

\author{
Jan Rossaint ${ }^{1}$, Jerry L Nadler ${ }^{2}$, Klaus Ley ${ }^{3}$ and Alexander Zarbock ${ }^{*}$
}

\begin{abstract}
Introduction: Acute lung injury (ALI) is a common disease in critically ill patients with a high morbidity and mortality. 12/15-lipoxygenase (12/15-LO) is an enzyme generating 12-hydroxy-eicosatetraenoic acid (12-HETE) and 15-HETE from arachidonic acid. It has been shown that 12/15-LO is involved in the regulation of vascular permeability during ALI.

Methods: To test whether 12/15-LO participates in leukocyte recruitment into the lung, we investigated the role of 12/15-LO in mouse models of lipopolysaccharide (LPS)-induced pulmonary inflammation and acid-induced ALI, a clinically relevant model of acute lung injury.

Results: The increase in neutrophil recruitment following LPS inhalation was reduced in 12/15-LO-deficient (Alox $15^{-1}$ ) mice and in wild-type (WT) mice after the blocking of 12/15-LO with a pharmacological inhibitor. Bone marrow chimeras revealed that 12/15-LO in hematopoietic cells regulates neutrophil accumulation in the interstitial and alveolar compartments, whereas the accumulation of neutrophils in the intravascular compartment is regulated by 12/15-LO in non-hematopoietic and hematopoietic cells. Mechanistically, the increased plasma levels of the chemokine CXCL1 in Alox15 $5^{-1}$ mice led to a reduced response of the neutrophil chemokine receptor CXCR2 to stimulation with CXCL1, which in turn abrogated neutrophil recruitment. Alox $15^{-1-}$ mice also showed decreased edema formation, reduced neutrophil recruitment and improved gas exchange in an acid-induced ALI model.
\end{abstract}

Conclusions: Our findings suggest that 12/15-LO modulates neutrophil recruitment into the lung by regulating chemokine/chemokine receptor homeostasis.

Keywords: lipoxygenase, acute lung injury, inflammation, leukocyte recruitment

\section{Introduction}

Acute lung injury (ALI) is a severe disease with a high incidence [1]. ALI is associated with high mortality despite improved treatment [1], causes 3.6 million hospital days per year, and thus is a huge burden for the health care system [1]. ALI can occur as a consequence of extrapulmonary causes, including massive transfusion and sepsis, and intrapulmonary causes, such as aspiration of gastric content and pneumonia. During the development of ALI, the alveolar-capillary integrity is compromised,

\footnotetext{
* Correspondence: zarbock@uni-muenster.de

'Department of Anesthesiology, Intensive Care and Pain Medicine, University of Münster, Albert-Schweitzer-Campus 1, Gebäude A1, Münster, 48149, Germany

Full list of author information is available at the end of the article
}

leading to neutrophil infiltration, interstitial and alveolar edema formation, and diminished gas exchange [2]. As yet, there are no specific treatments available for ALI.

Accumulation and recruitment of neutrophils to the lung are key events in the development of ALI [2]. Neutrophil recruitment to the lung occurs in a cascade-like process of activation, intravascular accumulation, and transendothelial and transepithelial migration [3]. Depending on the underlying cause of ALI, different chemokines and adhesion molecules participate in neutrophil recruitment [4]. It has been shown that CXCR2, the chemokine receptor for CXCL1 (keratinocyte-derived chemokine, KC) and CXCL2/3 (macrophage inflammatory protein 2, MIP-2) in the mouse system, is involved in the regulation of vascular permeability and in neutrophil recruitment in different
C Biomed Central

C 2012 Rossaint et al.; licensee BioMed Central Ltd. This is an open access article distributed under the terms of the Creative Commons Attribution License (http://creativecommons.org/licenses/by/2.0), which permits unrestricted use, distribution, and reproduction in any medium, provided the original work is properly cited. 
models of ALI [5-7]. Following lipopolysaccharide (LPS) inhalation, CXCR2 on non-hematopoietic and hematopoietic cells each contributes about equally to neutrophil recruitment into the lung [5]. Blocking of CXCR2 by a pharmacological inhibitor or elimination of CXCR2 in both cell types completely abolished neutrophil recruitment into the alveolar space in response to inhaled LPS $[5,7]$. A recently published study demonstrated that human CXCL8 (interleukin 8; IL-8), a ligand for human CXCR1 and CXCR2 [8] can form complexes with autoantibodies associated with the development and outcome of ALI in patients [9].

Besides chemokines, lipid mediators are critically involved in the development of pulmonary inflammation and play important roles in the pathophysiology of allergen-induced inflammation and lung remodeling in asthma $[10,11]$. Lipoxygenases (LOX) are a family of enzymes capable of incorporating oxygen into unsaturated fatty acids [12]. Their nomenclature depends upon the position of the carbon double bonds they oxidize counted from the carboxyl terminus of the fatty acid [13]. 15-lipoxygenase is expressed in humans and rabbits (15-LO) $[14,15]$. "Leukocyte-type" 12-LO, which has some 15-LO activity, is expressed in pigs, rats and mice [16]. A high homology exists between 12/15-LO in mice and 15-LO in humans. Thus, the murine $12 / 15$ - LO is most likely the mouse ortholog of human 15-LO $[17,18]$. The most common substrate for 12/15-LO, arachidonic acid, is released from membrane phospholipids by phospholipase A2 in response to inflammatory stimuli [19]. 12/15-LO metabolizes arachidonic acid. This process yields short-lived, peroxidized products, which are reduced or enzymatically converted to 12-hydroxyeicosatetraenoic acid (12-HETE) as well as hepoxilins, lipoxins and others [20]. 12/15-LO is expressed in a variety of tissues, with the highest expression levels in monocytes and macrophages [21]. Lower expression levels of 12/15-LO are found in endothelial cells [22] and other tissues. 12-HETE has a variety of biological functions. It is a potent, proinflammatory chemoattractant for neutrophils [23]. 12-HETE exerts effects on endothelial cells as it influences cytoskeleton rearrangement [24] and cytokine production [25]. 12-HETE may also induce adhesion molecule expression on endothelial cells [26]. Furthermore, an implication of $12 / 15$-LO in chronic inflammatory processes has been reported [21]. In a previous study, the development of allergic sensitization and airway inflammation has been demonstrated to be diminished in Alox $15^{-/}$ mice [11,27]. However, rabbits made transgenic for human Alox15 were protected from atherosclerosis [28] or $\mathrm{LTB}_{4}$ - or IL-8-induced dermatitis [29], possibly through protective metabolites. Besides 12/15-LO, the lipoxygenase 5-LO has been shown to be involved in inflammatory processes, for example, the ventilator-induced lung injury model [30]. We previously demonstrated that 12-HETE, the product of $12 / 15-\mathrm{LO}$, produced by hematopoietic cells plays a key role in the regulation of vascular permeability in LPS-induced pulmonary inflammation and acidinduced ALI through a CXCR2-dependent mechanism [31].

The aim of this study was to investigate the role of 12/15-lipoxygenase on neutrophil recruitment into the lung in murine models of LPS-induced pulmonary inflammation and acid-induced acute lung injury. To reveal the main source of 12/15-LO influencing neutrophil recruitment, chimeric mice were generated by bone marrow transplantation. To reveal the mechanisms by which 12/15-LO modulates neutrophil recruitment, we investigated the role of $12 / 15-\mathrm{LO}$ on the chemokine/chemokine receptor homeostasis.

\section{Materials and methods \\ Animals}

The animals used in this study were 8- to 12 -week old C57BL/6 mice (The Jackson Laboratory, Bar Harbor, ME, USA) and 12/15-LO deficient mice $\left(\right.$ Alox $\left.15^{-/}\right)$backcrossed to $\mathrm{C} 57 \mathrm{BL} / 6$ for at least 10 generations [32]. The mice were kept in a barrier facility under specific pathogen-free conditions. All animal experiments were approved by the Animal Care and Use Committees of the University of Virginia (Charlottesville) and the University of Münster (Germany).

\section{Murine model of LPS-induced pulmonary inflammation and acid-induced ALI}

For the induction of pulmonary inflammation, mice were placed in an enclosed chamber and exposed to nebulized LPS from Salmonella enteritidis $(500 \mu \mathrm{g} / \mathrm{ml}$, SigmaAldrich, St. Louis, MO, USA) for 30 minutes, as previously described [7]. Control mice were exposed to aerosolized, sterile saline for 30 minutes.

For some experiments, mice were injected with CDC (Cinnamyl-3,4-Dihydroxy-a-Cyanocinnamate, Biomol International, Philadelphia, PA, USA), a pharmacological inhibitor of 12/15-LO. Mice received a single injection $(8 \mathrm{mg} / \mathrm{kg}$, intraperitoneal (i.p.)) one hour before LPS application.

Acid-induced ALI was performed as previously described [33]. Briefly, after induction of general anesthesia with ketamine $(125 \mu \mathrm{g} / \mathrm{g}$ body weight; Sanofi-Aventis, Paris, France), xylazine (12.5 $\mu \mathrm{g} / \mathrm{g}$ body weight; Phoenix Scientific, Inc., St. Joseph, MO, USA), and atropine sulfate $(0.025 \mu \mathrm{g} / \mathrm{g}$ body weight; Fujisawa, Tokyo, Japan $)$ mice were placed on a heating pad and the ventral aspect of the neck was incised to gain access to the trachea. A total of $2 \mu \mathrm{l} / \mathrm{g} \mathrm{HCl}$ ( $\mathrm{pH} 1.5$ ) was injected intratracheally, followed by a bolus of air $(30 \mu \mathrm{l} / \mathrm{g})$. Tracheotomy was performed and mice were mechanically ventilated with a respirator (MiniVent Type 845, Hugo Sachs Elektronik, 
March-Hugstetten, Germany) for two hours (tidal volume $10 \mu \mathrm{l} / \mathrm{g}$; respiration rate $140 /$ minute; fraction of inspiratory oxygen $\left(\mathrm{FiO}_{2}\right)$ 0.21). Control animals were treated in the same way, except for the instillation of sterile saline instead of $\mathrm{HCl}$.

\section{Neutrophil recruitment into the lung}

Twenty-four hours after LPS-inhalation mice were euthanized. Bronchoalveolar lavage (BAL) fluid was collected $(5 \times 1 \mathrm{ml}$ phosphate-buffered saline). The BAL was centrifuged and the neutrophils in the BAL fluid were counted using Kimura staining.

Intravascular and interstitial neutrophils were distinguished by a flow cytometry-based method as described previously [33]. Briefly, Alexa 633-labeled GR-1 antibody (clone RB6-8C5, staining kit: Invitrogen Corp., Carlsbad, CA, USA) to murine neutrophils was injected intravenously five minutes prior to euthanasia. This procedure labels only intravascular neutrophils as the time period is not sufficient for the antibody to react with neutrophils located in the interstitial or intraalveolar compartment. Thoracotomy was performed, the inferior vena cava was opened and non-adherent neutrophils were removed from the pulmonary vasculature by perfusing the right ventricle with $3 \mathrm{ml}$ of saline with a constant pressure of $25 \mathrm{cmH}_{2} \mathrm{O}$. After collection of the BAL, the lungs were removed, minced and digested with an enzyme cocktail (collagenase type XI, hyaluronidase type I-s, DNAse1, Sigma-Aldrich, St. Louis, MO, USA) containing $65 \mu \mathrm{g}$ unlabelled GR-1antibody at $37^{\circ} \mathrm{C}$ for 60 minutes. A cell suspension was made by passing the digested lung tissue through a $70 \mu \mathrm{m}$ cell strainer (BD Falcon, Bedford, MA, USA). Red blood cells were lysed and the remaining leukocytes were resuspended in PBS and counted. The fraction of neutrophils in the suspension was determined by flow cytometry (FacsCalibur; BD Biosciences, San Jose, CA, USA). Neutrophils were identified by their typical appearance in the forward/ sideward scatter (FSC/SSC) and their expression of CD45 (clone 30-F11), 7/4 (clone 7/4, both BD Pharmingen, San Diego, CA, USA), and GR-1 (clone RB6-8C5, purified from hybridoma supernatant). The labelled GR-1-antibody was used to differentiate between intravascular $\left(\mathrm{CD} 45^{+} 7 / 4\right.$ $\left.{ }^{+} \mathrm{GR}-1^{+}\right)$and interstitial $\left(\mathrm{CD} 45^{+} 7 / 4^{+} \mathrm{GR}-1^{-}\right)$neutrophils.

\section{In vitro chemotaxis assay}

The in vitro chemotaxis assay was performed as described previously [5]. For the in vitro chemotaxis assay, isolated neutrophils were labeled with calcein AM ( $5 \mu \mathrm{M}$; Molecular Probes, Eugene, OR, USA) [34]. A 96-well chemotaxis system (ChemoTx, 3- $\mu \mathrm{m}$ filter pore size; Neuro Probe, Inc., Gaithersburg, MD, USA) was loaded with triplicates of recombinant CXCL1 (1-10,000 ng/ml; PeproTech, Rocky Hill, NJ, USA) or fMLP ( $\mathrm{n}$-formyl-methionine- leucine-phenylalanine, 1 to 10,000 ng/ml; Sigma-Aldrich, Taufkirchen, Germany). Neutrophil suspension $\left(2.5 \times 10^{5}\right)$ was placed on top of the filter above each well, and the chamber was incubated for one hour at $37^{\circ} \mathrm{C}$ [5]. After incubation, non-migrated cells and the filter were removed and fluorescence in the wells was measured with a fluorescence plate reader.

\section{Generation of 12/15-Lipoxygenase chimeric mice}

To investigate the role of 12/15-Lipoxygenase from nonand hematopoietic origin in pulmonary inflammation, we generated chimeric mice as described previously [33]. Destruction of the native bone marrow in male recipient mice was archived by fractional lethal irradiation in two doses of 600 rad each (separated by four hours). WT (C57BL/6) and 12/15-lipoxygenase-deficient mice served as donors and/or recipients. The bone marrow isolation from donor mice was performed under sterile conditions. Approximately $5 \times 10^{6}$ cells were injected intravenously into irradiated recipient mice. Experiments with chimeric mice were performed six weeks after successful bone marrow transplantation.

\section{Histology}

To investigate changes in tissue morphology following LPS-induced pulmonary inflammation, lungs were removed, embedded in paraffin and cut in $5 \mu \mathrm{m}$ thick slices. Tissue samples were stained for CXCL1 (anti-murine KC, PeproTech, Rocky Hill, NJ, USA) using the avidinbiotin technique (Vector Laboratories, Burlingame, CA, USA) as described previously [35].

\section{Surface staining and flow cytometry analysis}

We analyzed the surface expression of CXCR2 on peripheral blood leukocytes by incubating whole blood samples with CD45 (clone 30-F11), 7/4 (clone 7/4, both BD Biosciences-Pharmingen, San Diego, CA, USA), GR-1 (clone RB6-8C5), and CXCR2 (clone 242216, R\&D Systems, Inc., Minneapolis, MN, USA). After red blood cell lysis with $1.5 \mathrm{M} \mathrm{NH}_{4} \mathrm{Cl}$, flow cytometry was performed to quantitatively determine surface expression of CXCR2 (FacsCalibur, BD Biosciences, Franklin Lakes, NJ, USA).

\section{CXCL1/2 measurement}

CXCL1 and CXCL2 levels in the plasma with and without LPS challenge were measured in triplicates using ELISA kits according to the manufacturer's protocol (R\&D Systems, Minneapolis, MN, USA). In order to measure CXCL1 and CXCL2 in the lung tissue, lungs were mechanically minced and incubated with extraction buffer containing $0.1 \%$ Triton X-100, $10 \mathrm{mM}$ EDTA, $100 \mathrm{mM}$ e-aminocaproic acid, $0.01 \mathrm{mM}$ Pepstatin, $0.005 \mathrm{mM}$ Leupeptin and $50 \mathrm{mM}$ Tris at $4^{\circ} \mathrm{C}$ for 
18 hours. Samples were centrifuged and the CXCL1 and CXCL2 concentration in the supernatant was quantified using the ELISA kits as described above.

\section{Statistics}

Statistical analysis was performed with SPSS (version 9.0; SPSS, Inc., Chicago, IL, USA). Statistical tests included one-way analysis of variance, Student-Newman-Keuls test, and t-test where appropriate. All data are presented as mean $\pm \mathrm{SEM}, P<0.05$ was considered significant.

\section{Results}

12/15-lipoxygenase is involved in LPS-induced pulmonary inflammation

In order to investigate the role of 12/15-lipoxygenase in pulmonary inflammation, mice were exposed to aerosolized LPS for 30 minutes and neutrophil recruitment into the different compartments of the lung was determined by flow cytometry. In this model, neutrophil recruitment into the lung peaks at 24 $\mathrm{h}$ after LPS inhalation [3]. After LPS inhalation, the number of neutrophils transmigrated into the interstitial compartment significantly increased in all mice, but significantly less in Alox $15^{-/-}$mice than in WT mice (Figure 1A). LPS induced an increase of neutrophils in the alveolar space in WT mice, which was reduced by two-thirds in Alox $15^{-/}$mice (Figure 1B). Elimination of 12/15-LO in Alox $15^{-/-}$mice decreased pulmonary edema formation as measured by wet/dry ratio after LPS exposure (Figure 1C) and decreased histological signs of lung tissue damage (Figure 1D-G). Differential white blood cell counts were not different between WT and Alox $15^{-/-}$ mice. All mice survived the 24-hour observation period following LPS administration.

\section{Pharmacological inhibition of 12/15-LO reduces neutrophil recruitment}

In order to investigate if the acute blockade of $12 / 15$-LO with a pharmacological inhibitor also reduces neutrophil recruitment, mice were treated with the 12/15-LO inhibitor CDC one hour before LPS exposure. A single injection of $8 \mathrm{mg} / \mathrm{kg}$ CDC significantly reduced the 12/15-LO activity, as measured by urinary 12-HETE concentration $24 \mathrm{~h}$ later [36]. Pharmacological inhibition of 12/15-LO significantly decreased neutrophil accumulation in the intravascular (Figure 2A), interstitial (Figure 2B) and alveolar compartments (Figure 2C), decreased pulmonary edema formation (Figure 2D) and decreased the histological signs of lung injury (Figure 2E-H) compared to control mice.

\section{Hematopoietic and non-hematopoietic $12 / 15$-LO is responsible for different steps of neutrophil recruitment into the lung}

In order to distinguish between the role of hematopoietic and non-hematopoietic 12/15-LO for neutrophil recruitment, chimeric mice were generated by bonemarrow transplantation. Elimination of either hematopoietic or non-hematopoietic 12/15-LO had no effect on neutrophil accumulation in the intravascular compartment (Figure 3A). Only mice lacking 12/15-LO in both the hematopoietic and non-hematopoietic compartments showed significantly reduced accumulation of neutrophils in the intravascular compartment (Figure 3A), similar to Alo $\times 15^{-/-}$mice (data not shown). The transmigration of neutrophils into the interstitial and alveolar compartment in response to LPS inhalation was reduced in mice lacking 12/15-LO either in the hematopoietic or both compartments (Figure 3B, C).

\section{Elimination of $12 / 15$-LO activity alters chemokine homeostasis}

The chemokines CXCL1 and CXCL2 and their receptor CXCR2 are critically involved in the development of pulmonary inflammation and ALI $[5,6,37,38]$. Therefore, we measured plasma CXCL1 and CXCL2 concentrations in WT mice and Alox $15^{-/-}$mice under baseline conditions and $3 \mathrm{~h}$ after LPS inhalation. Alox $15^{-/-}$mice showed significantly higher CXCL1 and CXCL2 plasma concentrations under baseline conditions compared to WT mice (Figure 4A, B). After LPS exposure, CXCL1 and CXCL2 plasma concentrations were elevated in WT mice and Alox $15^{-/-}$mice and remained higher in Alox $15^{-/-}$mice as in WT mice. Similar to the chemokine concentrations in the plasma, CXCL1 and CXCL2 concentrations in the lung tissue were also higher under baseline conditions and three hours after LPS exposure in Alox $15^{-/-}$mice compared to WT mice (Figure 4C, D). Comparable to genetic ablation of Alox15, pharmacological blockade of 12/15-LO in WT mice caused increased CXCL1 plasma levels (Figure 4E) and decreased CXCR2 expression on circulating neutrophils (Figure 4F) compared to vehicletreated control mice under baseline conditions and after LPS exposure. In order to investigate the location of the CXCL1-producing cells, we conducted immunohistochemistry of the lung for CXCL1. WT mice without LPS inhalation showed almost no CXCL1-producing cells in the lung (Figure 4G), whereas the number of CXCL1-producing cells increased upon LPS exposure (Figure 4H). Lungs from Alox $15^{-/-}$mice showed some CXCL1-producing cells under baseline conditions (Figure 4I) and more after LPS inhalation (Figure 4J).

\section{Reduced response of neutrophils to CXCL1}

In order to study the consequences of the altered chemokine homeostasis in Alox $15^{-/-}$mice, we investigated CXCR2 expression on neutrophils. The elevated CXCL1 concentration in the plasma of Alox $15^{-/-}$mice led to a significant down-regulation of CXCR2 on the surface of peripheral blood neutrophils from $33 \pm 4$ to $20 \pm 3$ mean 

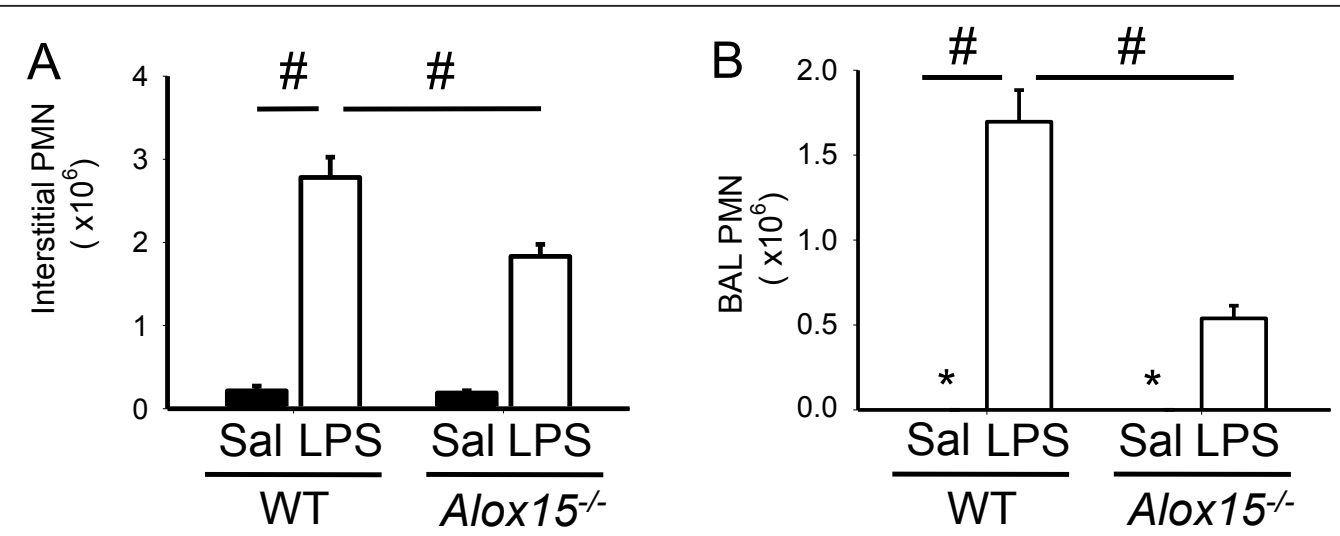

$\mathrm{C}$

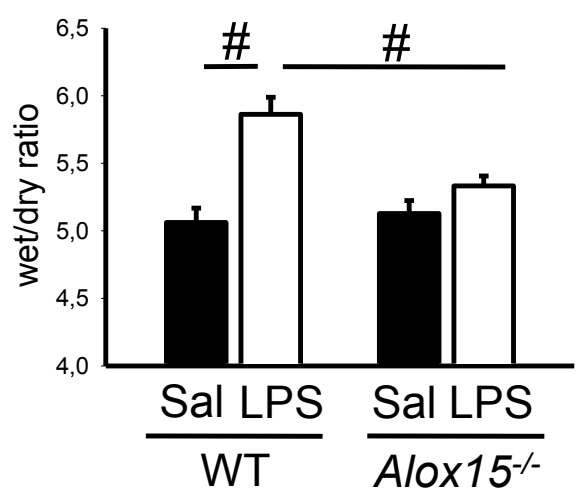

WT

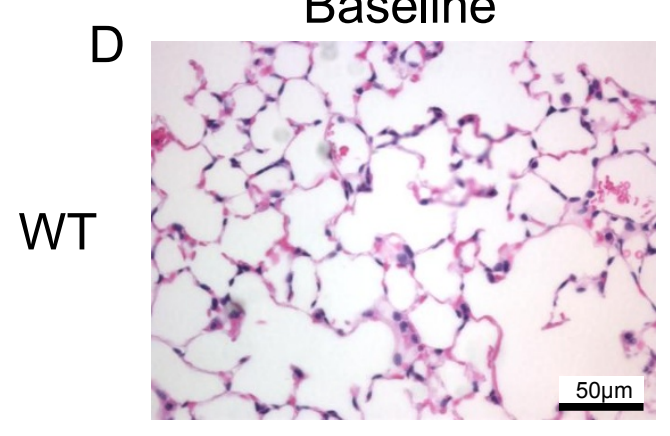

$\mathrm{E}$

LPS exposure
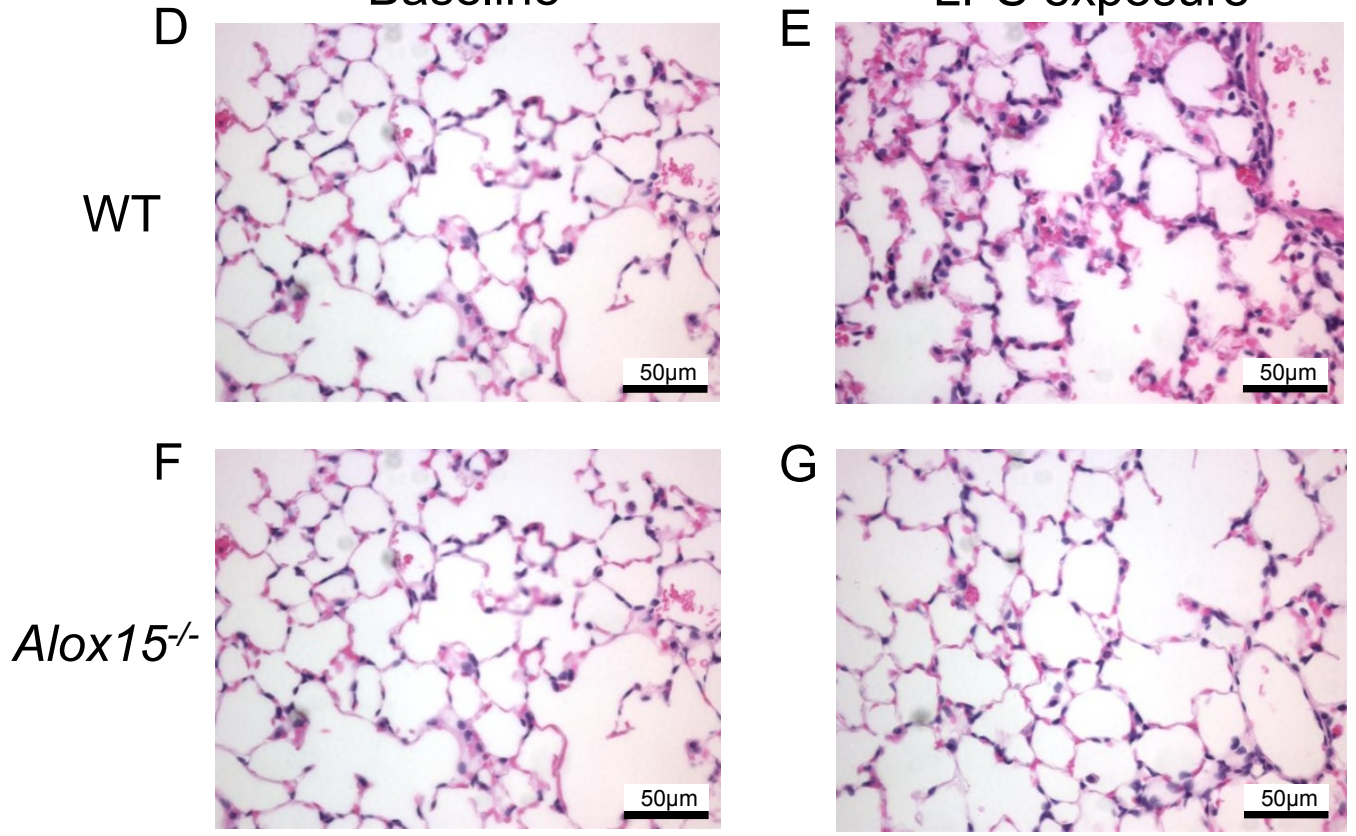

Figure 1 12/15-lipoxygenase is involved in LPS-induced pulmonary inflammation. Neutrophil recruitment into the interstitial (A) and BAL

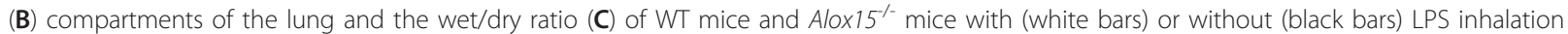
(24 h) was measured by flow cytometry ( $n=3$ to 4). Exemplary histological images of lungs from WT mice and Alox $15^{-1}$ mice under baseline conditions and after LPS exposure (D-G). Bar indicates $50 \mu \mathrm{m} .{ }^{*} P<0.05,{ }^{*} P<0.05$ versus WT LPS. 

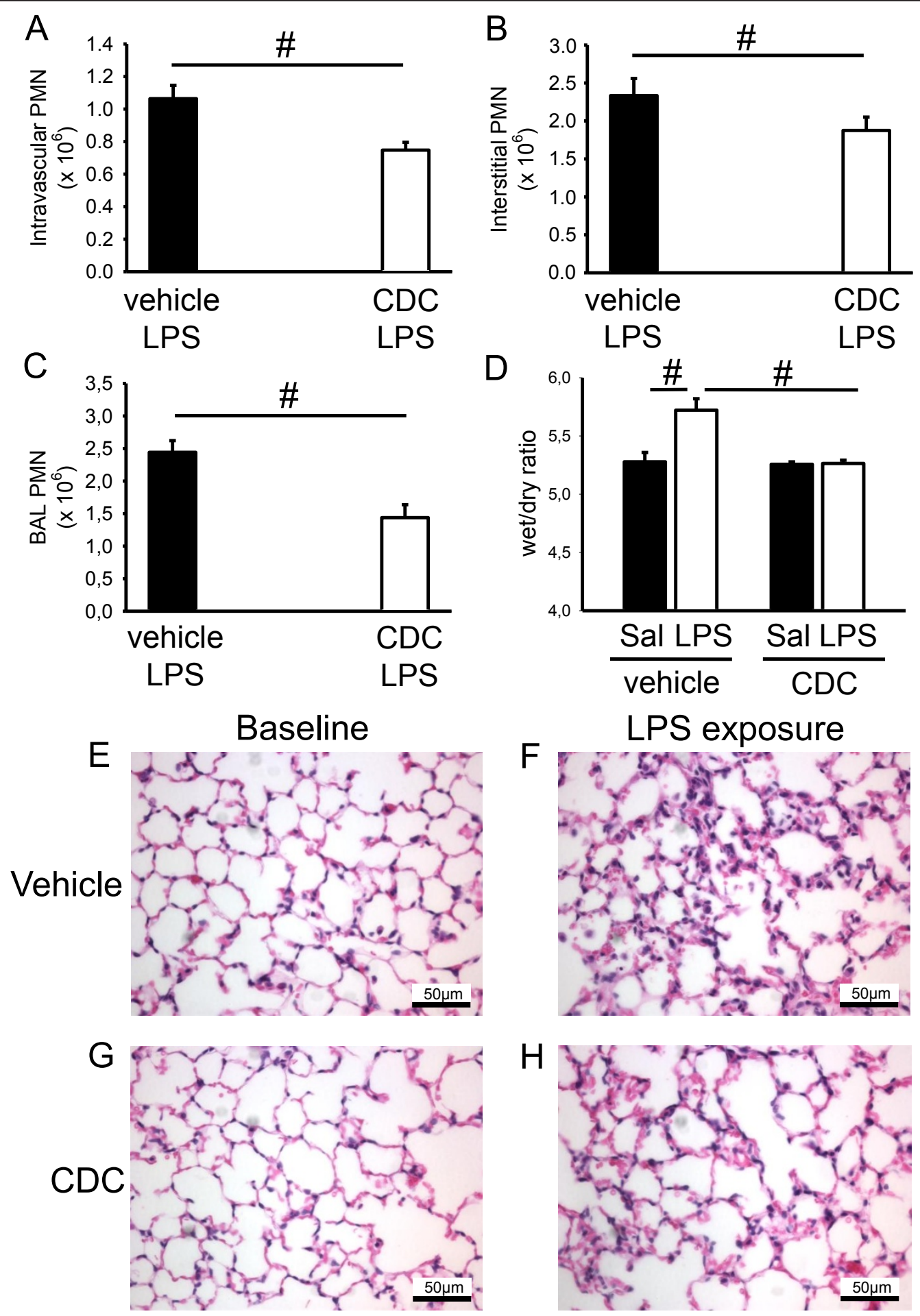

Figure 2 Pharmacological inhibition of 12/15-LO reduces neutrophil recruitment. (A-C) After pharmacological blockade of 12/15-LO by the inhibitor CDC (Cinnamyl-3,4-Dihydroxy-a-Cyanocinnamate) or in vehicle control mice, neutrophil recruitment (24 h) into the lung was investigated by flow cytometry. Number of neutrophils in the intravascular (A), interstitial (B), and alveolar compartments $(C)(n=4)$. Wet/dry ratio under baseline conditions and after LPS exposure $(\mathbf{D})(n=3)$. Exemplary histological images of lungs from WT mice and Alox $15^{-1-}$ mice under baseline conditions and after LPS exposure (E-H). Bar indicates $50 \mu \mathrm{m} .{ }^{\#} P<0.05$ 


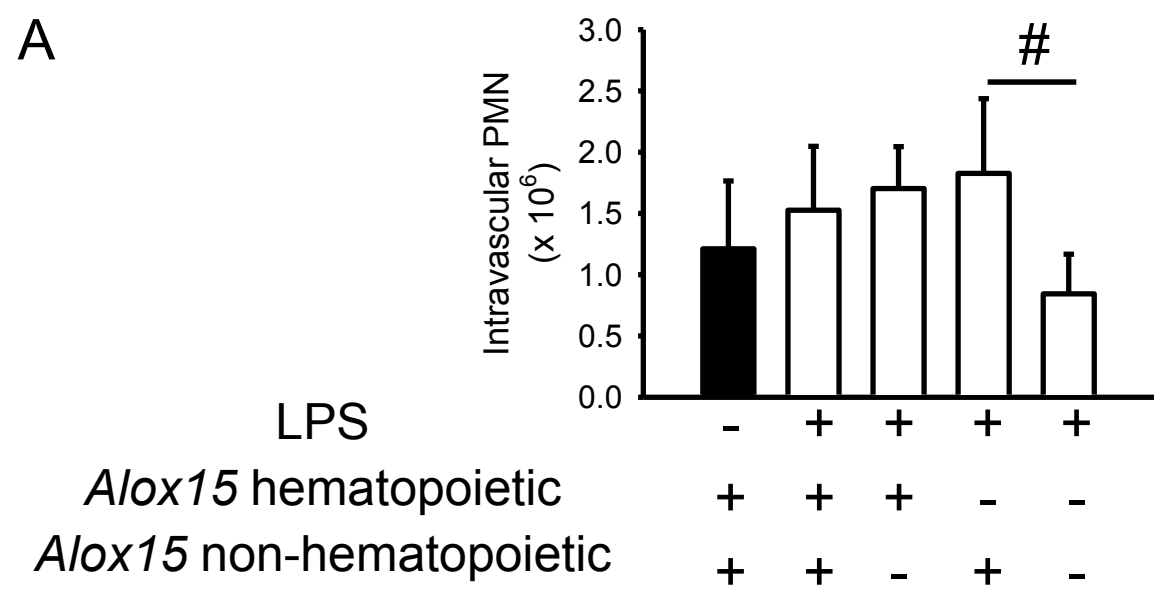

$\mathrm{B}$
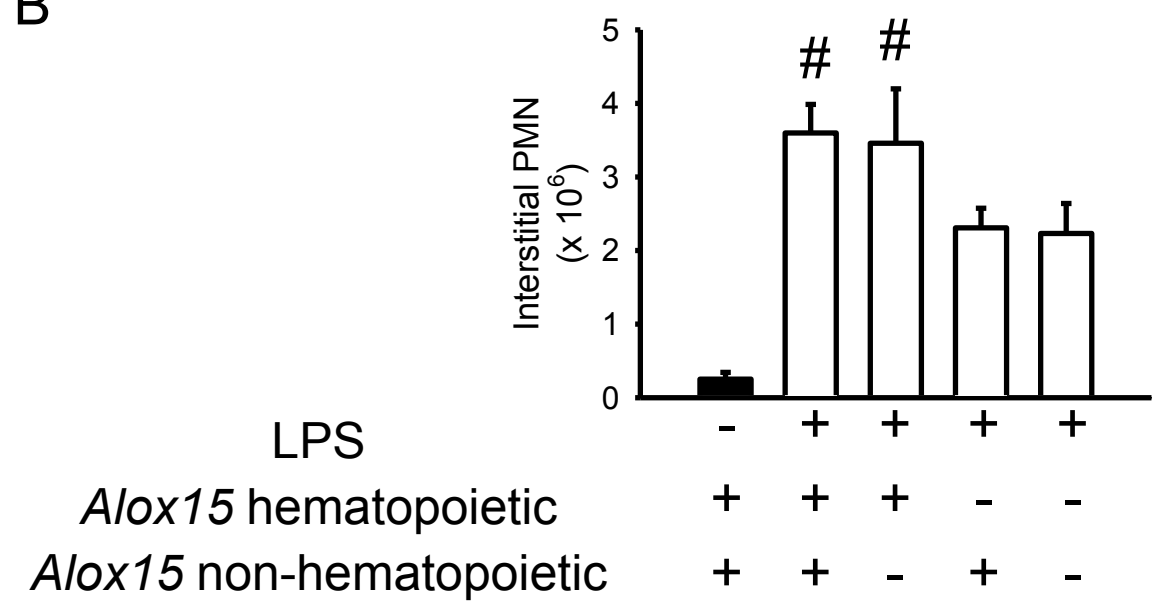

C
LPS

\section{Alox15 hematopoietic}

\section{Alox15 non-hematopoietic}

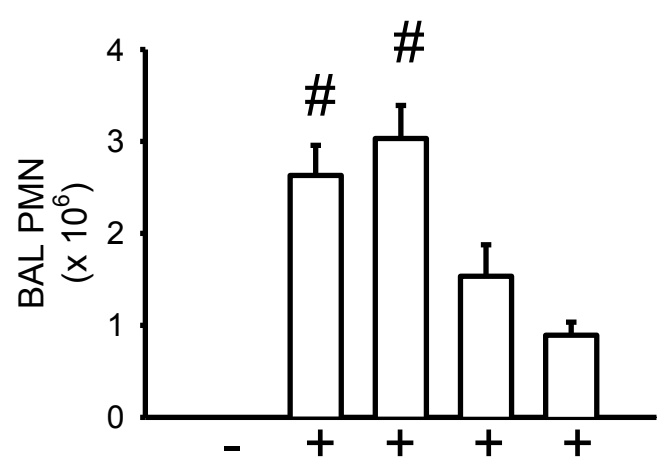

Figure 3 Hematopoietic 12/15-LO is responsible for the regulation of neutrophil recruitment into the lung. Neutrophil recruitment into the lung in response to LPS (white bars) was tested in BM chimeras (WT into WT; WT into Alox $15^{-1}$; Alox $15^{-/-}$into WT; Alox $15^{-1-}$ into Alox $15^{-/}$) ( $n=$ 4 to 5 mice per group). Mice lacking hematopoietic and non-hematopoietic Alox 15 showed a reduced neutrophil accumulation in the intravascular compartment $24 \mathrm{~h}$ after LPS inhalation (A). Reduced neutrophil recruitment into the interstitial (B) and alveolar (C) compartment was observed when either hematopoietic or both hematopoietic and non-hematopoietic Alox15 was eliminated. $\mathrm{n}=4$ to 5 . \# $P<0.05$. 

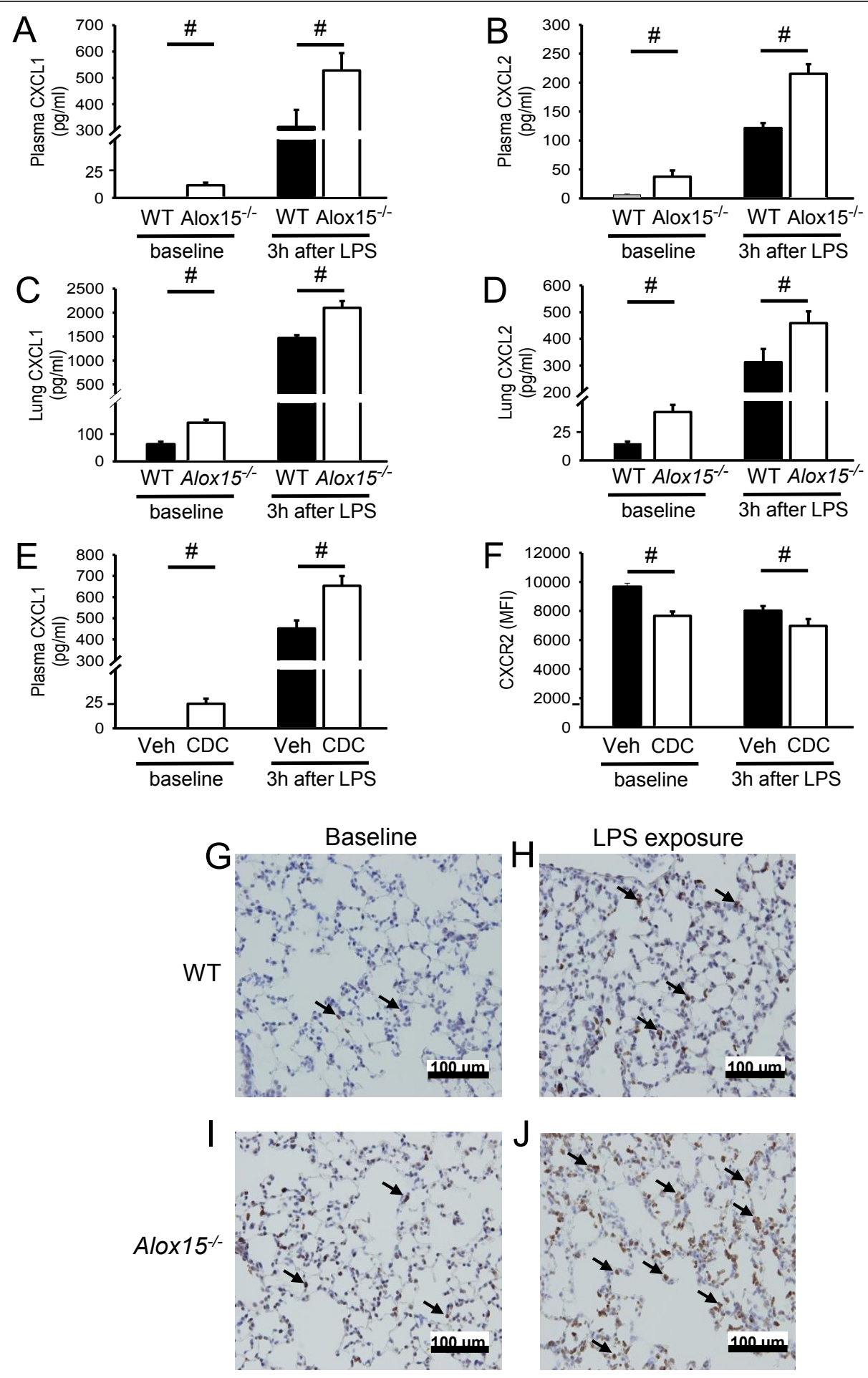

Figure 4 Elimination of 12/15-LO activity alters chemokine homeostasis. CXCL1 (A) and CXCL2 (B) concentrations in the plasma was

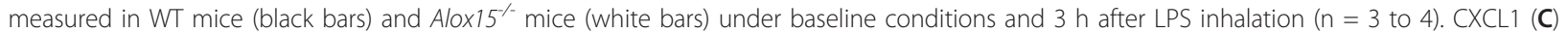
and CXCL2 (D) concentrations in the lung were measured in WT mice (black bars) and Alox $15^{-}$mice (white bars) under baseline conditions and $3 \mathrm{~h}$ after LPS inhalation ( $\mathrm{n}=3$ to 4). CXCL1 concentration (E) was measured in the plasma of vehicle- or CDC-treated WT mice and CXCR2 expression (F) on circulating neutrophils under baseline conditions and $3 \mathrm{~h}$ after LPS inhalation was quantified by using flow cytometry ( $\mathrm{n}=3$ ). (G-J) CXCL1 protein expression shown by immunohistochemistry in WT and Alox $15^{-1}$ mice under baseline conditions and $3 \mathrm{~h}$ after LPS inhalation. Black arrows indicate CXCL1-producing cells $(n=3)$. Bar indicates $100 \mu \mathrm{m}$. ${ }^{\#} P<0.05$ 
fluorescence intensity units $(\mathrm{n}=3)$ as measured by flow cytometry (Figure 5A). In order to show that the elevated CXCL1 concentration observed in Alox $15^{-/-}$mice indeed causes the down-regulation of CXCR2 on the neutrophil surface, we incubated isolated neutrophils from WT mice with CXCL1 at a concentration of $10 \mathrm{pg} / \mathrm{ml}$ (as measured in the BAL of Alox $15^{-/-}$mice under baseline conditions) at $37^{\circ} \mathrm{C}$ for one hour and could observe a significantly reduced CXCR2 expression from $35 \pm 3$ to $18 \pm 3$ mean fluorescence intensity units $(\mathrm{n}=3)$ in untreated neutrophils (Figure 5B). To test the functional consequences of CXCR2 down-regulation, an in vitro chemotaxis assay was performed. Bone marrow-derived neutrophils from both Alox $15^{-1-}$ and WT mice showed the same low migration rate without a chemoattractant. Neutrophils from WT mice migrated vigorously towards low concentrations of CXCL1 $(10 \mathrm{ng} / \mathrm{ml})$, whereas neutrophils from Alox $15^{-/-}$mice showed a very small response. High CXCL1 concentrations (500 to $10,000 \mathrm{ng} / \mathrm{ml}$ ) induced similar migration rates in neutrophils from WT and Alox $15^{-/}$mice. We calculated the chemotactic index (migrated cells with chemoattractant/without chemoattractant) and determined $\mathrm{ED}_{50}$ as $4.5 \mathrm{ng} / \mathrm{ml}$ in WT mice and $40 \mathrm{ng} / \mathrm{ml}$ in Alox $15^{-/-}$mice (Figure 5C). In order to

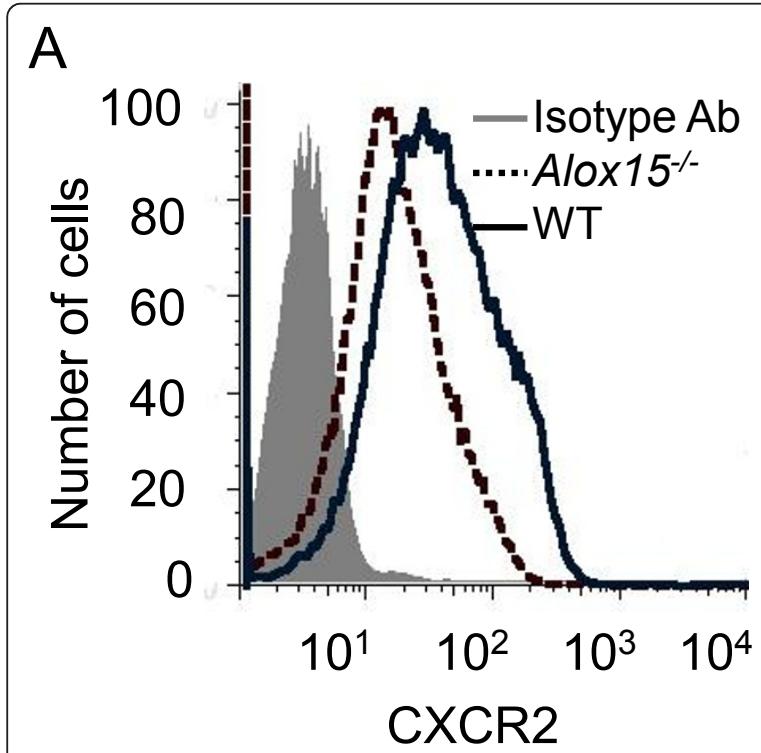

B

C
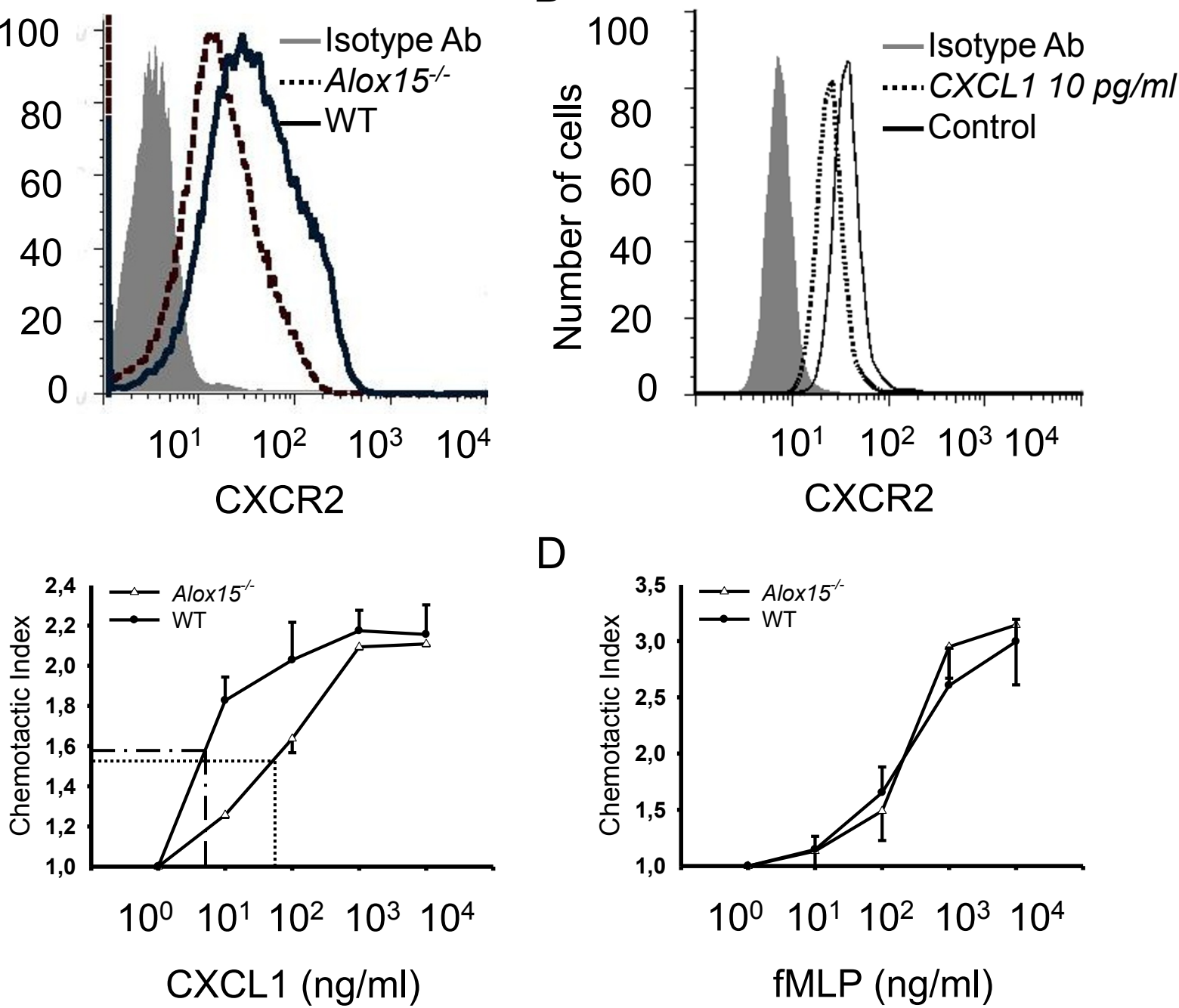

D

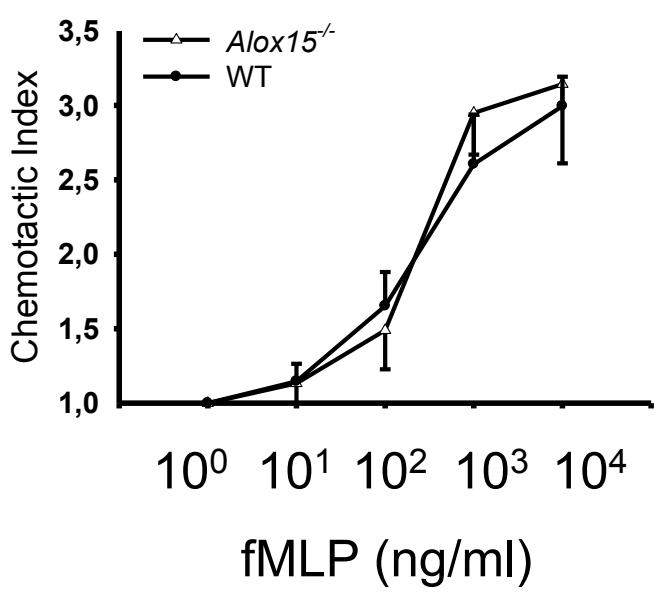

Figure 5 Elimination of 12/15-LO leads to a reduced response of neutrophils to CXCL1. (A) Flow cytometry analysis of CXCR2 expression was performed on peripheral blood neutrophils from WT and Alox $15^{-/}$mice under baseline conditions. Whole blood was stained for CD45, 7/4, GR-1 and CXCR2. CXCR2 expression on the surface of peripheral blood neutrophils was determined by using flow cytometry. ( $n=3)$. (B) Flow cytometry analysis of CXCR2 expression on isolated neutrophils treated with or without CXCL1 $(10 \mathrm{pg} / \mathrm{ml})$ for one hour $(\mathrm{n}=6)$. Migration of labeled neutrophils from WT mice (circles) and Alox $15^{-1-}$ mice (triangles) toward different concentrations of CXCL1 (C) or fMLP (D) was investigated in an in vitro chemotaxis assay. Neutrophils were applied on the top of the filter and allowed to migrate toward the chemoattractant for one hour at $37^{\circ} \mathrm{C}$. Migrated cells were measured by fluorescence intensity. Chemotactic index was calculated as the ratio of migrated cells with chemoattractant to migrated cells without chemoattractant and $\mathrm{ED}_{50}$ was determined $(n=3)$. 
show that the lack or blockade of $12 / 15$-LO specifically abrogates CXCR2-dependent migration, we performed additional chemotaxis assays with the chemoattractant fMLP ( $\mathrm{n}$-formyl-methionine-leucine-phenylalanine). There was no difference in the chemotactic index between WT and Alox $15^{-/}$neutrophils (Figure 5D). Taken together, the increased CXCL1 concentration in the plasma of Alox $15^{-/-}$mice led to reduced response of neutrophils to CXCL1 through a reduced expression of the chemokine-receptor CXCR2 on the cell surface. This and perhaps other desensitization effects led to a reduced neutrophil migration response to physiologically relevant concentrations of CXCL1.

\section{2/15-LO regulates neutrophil recruitment in acid- induced acute lung injury}

Based on our finding that the absence of 12/15-LO reduces neutrophil recruitment in response to aerosolized LPS, we hypothesized that this enzyme and its products may also regulate neutrophil recruitment in a clinically relevant model of acid-induced ALI [33]. Two hours after induction of ALI, WT mice showed significantly elevated neutrophil numbers in the BAL (Figure 6A), an increased wet/dry ratio (Figure $6 \mathrm{~B}$ ) and compromised gas exchanges, as measured by the $\mathrm{paO}_{2} / \mathrm{FiO}_{2}$ ratio (Figure 6C), which was significantly attenuated in Alox $15^{-/-}$mice. In addition, the histological hallmarks of acute lung injury, that is, invasion of immune cells, thickening of the interstitial membrane and protein extravasation, were reduced in Alox $15^{-/}$mice compared to WT animals, suggesting that $12 / 15-\mathrm{LO}$ regulates neutrophil recruitment and affects edema formation in acid-induced lung injury (Figure 6D-G). Similarly to genetic ablation of Alox 15, the pharmacological blockade of $12 / 15$-LO decreased the wet/dry ratio (Figure 7A), improved the gas exchange (Figure 7B) and dampened the histological evidence of acute lung injury in tissue samples (Figure 7C-F) in WT mice treated with $\mathrm{CDC}$ compared to vehicle-treated control animals.

\section{Discussion}

Our findings suggest that $12 / 15-\mathrm{LO}$ is critically involved in the regulation of neutrophil recruitment into the different compartments of the lung in LPS-induced pulmonary inflammation and acid-induced ALI. Eliminating or blocking 12/15-LO reduced neutrophil recruitment into the lung in different models of ALI. By using chimeric mice, we demonstrated that hematopoietic and non-hematopoietic $12 / 15$-LO is responsible for different steps of neutrophil recruitment into the lung. Elimination of 12/15-LO reduces neutrophil recruitment into the lung by modulating chemokine/chemokine receptor homeostasis. .

Several studies established the role of $12 / 15$-LO in different chronic inflammatory diseases, including arthritis
[39], atherosclerosis [21,40,41] and diabetes [42]. Two products of 12/15-LO, 5-HETE and 12-HETE, have been shown to be implicated in the regulation of vascular permeability during pulmonary inflammation following Gram-negative endotoxemia [43]. A recently published study demonstrated that 12/15-LO-derived 12-HETE regulates vascular permeability in acute lung injury through a CXCR2-dependent mechanism [31]. In previous studies, the elimination or pharmacological blockade of 12/15-LO positively influenced disease outcome, and blocking 12/15-LO has been proposed as a possible anti-inflammatory therapy $[44,45]$. However, the products of 12/15-LO are different in humans (mainly 15HETE) and mice (mainly 12-HETE). Here, we show that 12/15-LO regulates neutrophil recruitment into the lung during ALI.

It has been shown that different factors, including different adhesion molecules and chemoattractants, influence neutrophil recruitment into the lung during ALI. It has been demonstrated that the CXCL1-CXCR2 axis is the main factor influencing neutrophil recruitment during ALI $[5,7]$. Although other chemoattractant factors can influence neutrophil recruitment into the lung [46], a small reduction of CXCR2 on the cell surface may have a substantial impact on neutrophil recruitment [6]. Our data showing that the elimination or pharmacological blockade of 12/15-LO modulates chemokine hemostasis and neutrophil recruitment suggest that mainly the reduced surface expression of CXCR2 is responsible for the diminished severity of ALI. However, we cannot exclude that blocking or eliminating 12/15-LO influences other factors that regulate neutrophil recruitment.

Macrophage-derived 12/15-LO plays an essential role in the development of atherosclerosis in the apoE $E^{-1-}$ model [21]. Similar to this study, we show that 12/15LO expression in hematopoietic cells plays an important role in acute lung injury as measured by interstitial and alveolar neutrophil content. However, non-hematopoietic $12 / 15-\mathrm{LO}$ is also involved in neutrophil accumulation in the vasculature of the lung. This finding is consistent with the known expression of 12/15-LO in endothelial cells, where the products of the enzyme induce the expression of inflammatory adhesion molecules $[26,47]$. In the pulmonary vasculature, endothelial cells play an active role in neutrophil recruitment. A recent study has shown that endothelial $G \alpha_{i 2}$ is critical for eosinophil recruitment in ovalbumin-induced allergic airway inflammation [48].

The inhibitory effect on neutrophil recruitment into the different compartments of the lung was stronger in 12/15LO knockout mice than after pharmacological blockade of 12/15-LO. This effect can be explained by the pharmacokinetics of the inhibitor CDC during the 24 hours between LPS inhalation and mice sacrifice. 


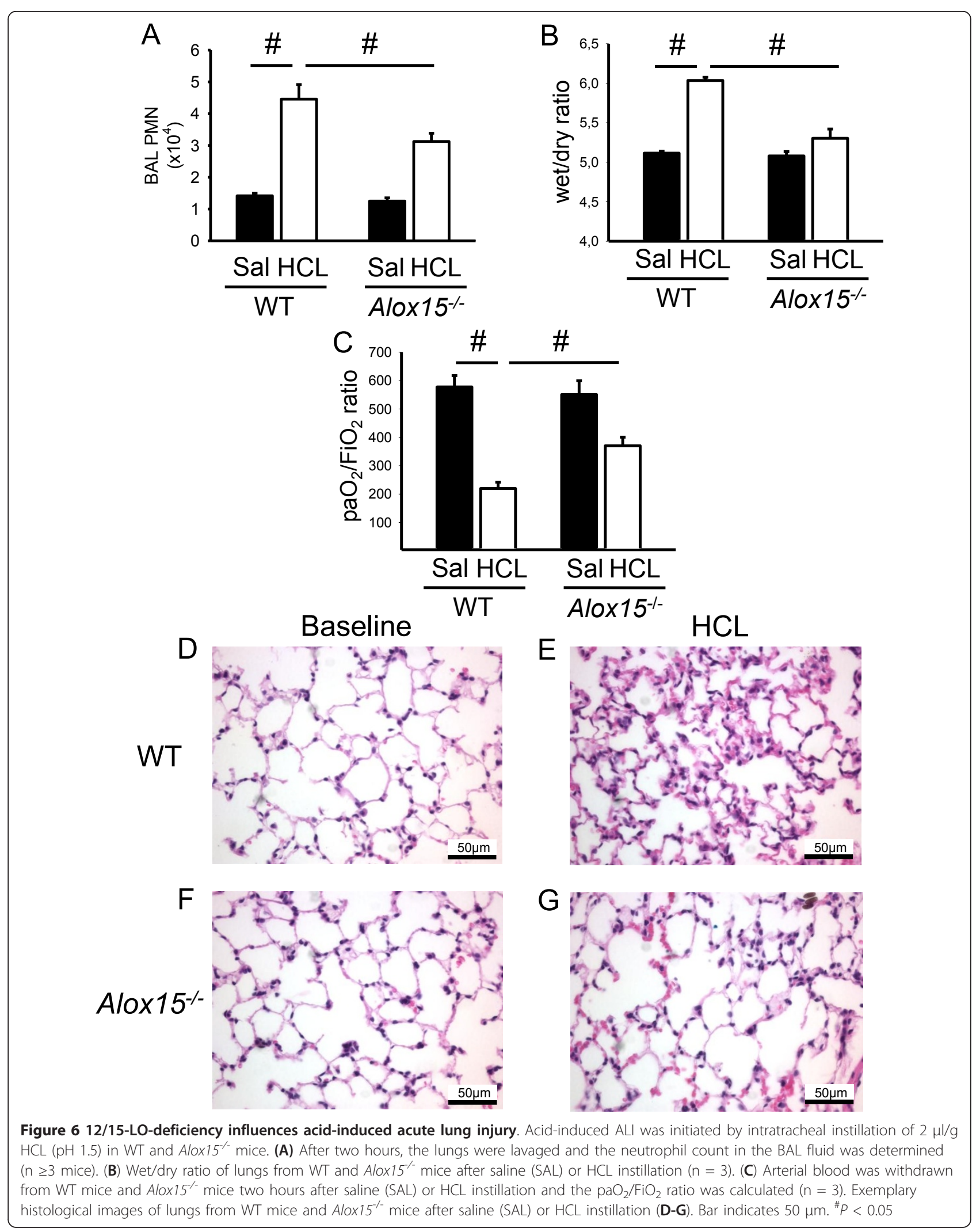




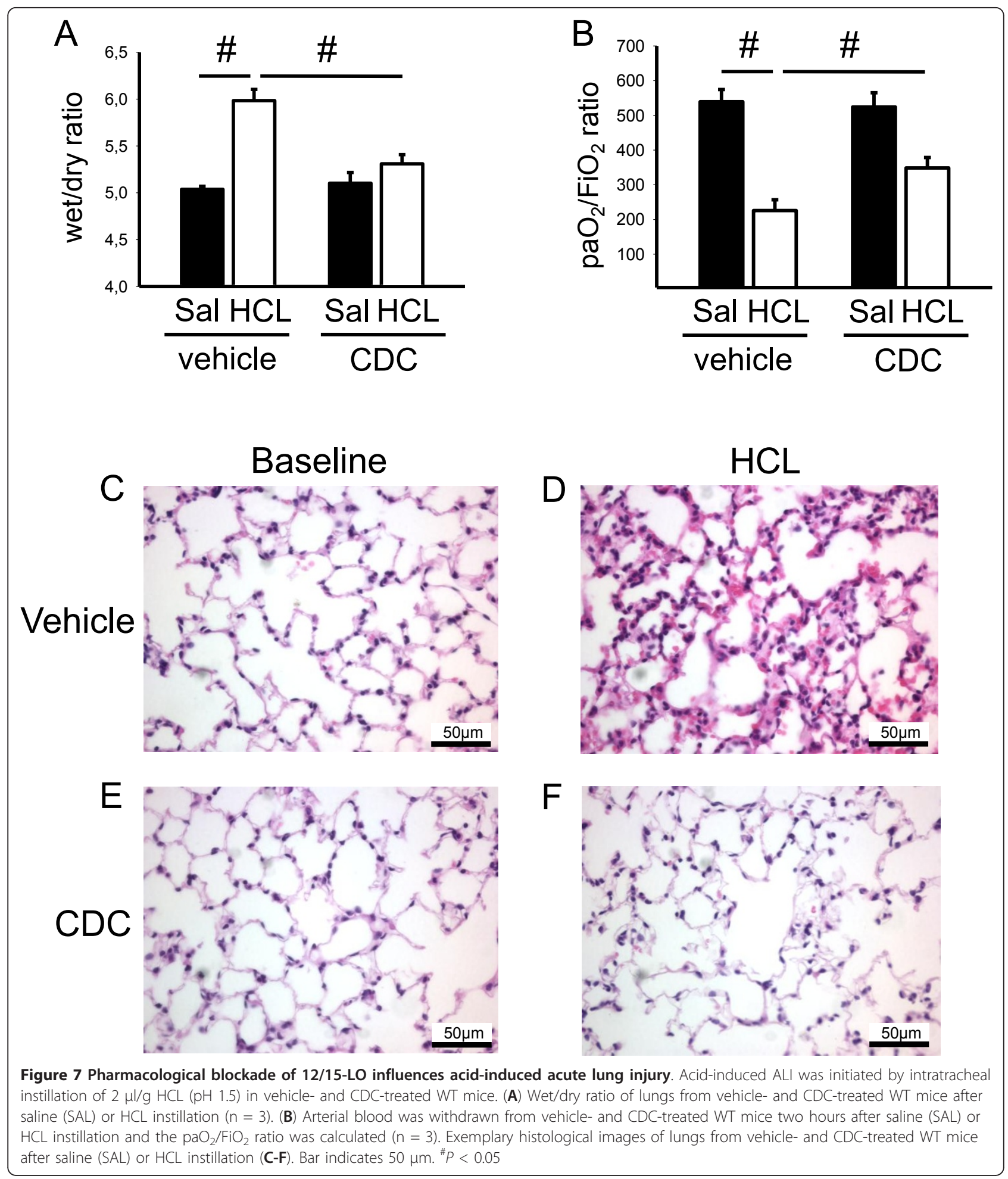

The main pro-inflammatory product of $12 / 15-\mathrm{LO}$ is 12-HETE [43]. Recently, the G protein-coupled receptor GPR31 has been proposed as a receptor for 12-HETE [49]. Knockdown of GPR31 inhibits 12-HETE-induced cell invasion by PC-3M cells [49]. However, it is still unknown whether the stimulation of GPR31 with 12HETE also regulates vascular permeability, neutrophil recruitment and chemokine release. There is evidence that the stimulation of neutrophils with 12-HETE activates a cascade of downstream molecules, including 
phosphoinositide 3-kinase, p21-activated kinase (PAK) [50] and p38 mitogen-activated protein kinase [51]. Even though the signaling cascade downstream of 12-HETE is still unknown, the implication of PAK may be a hint for a possible mechanism for the neutrophil effects of 12HETE. A recent study demonstrated that PAK in neutrophils influences migration into the lung following LPS stimulation [52].

As $12 / 15$-LO produces pro- and anti-inflammatory mediators, the biology of this enzyme is very complex [53]. 12/15-LO is involved in the biosynthesis of 12- and 15-HETE, 13 hydroxyoctadecadienoic acid and lipoxins [54]. 15-HETE and lipoxins have been reported to exert anti-inflammatory activities $[55,56]$. 15-HETE reduces activation and recruitment of inflammatory cells and modulates the expression of adhesion molecules $[57,58]$. $12 / 15-\mathrm{LO}$ is also involved in the production of the antiinflammatory eicosanoid lipoxin A4 (LXA4). Elimination of 12/15-LO leads to a reduced expression of LXA4 [39]. LXA4 acts by reducing chemokine-sensitivity and consecutively expression of adhesion molecules of effector cells and thus limiting the inflammatory response [59]. These results are well in accordance with our observations that the elimination of $12 / 15$-LO leads to increased CXCL1 levels under baseline and inflammatory conditions. This altered chemokine homeostasis causes the reduced expression of CXCR2 on neutrophils and leads to the diminished neutrophil recruitment into the lung in ALI. We observed a decreased in vitro chemotaxis of neutrophils from Alox $15^{-1-}$ mice towards lower concentrations of CXCL1 while the chemotactic response was similar at high CXCL1 concentrations. This goes along with the observed CXCL1 concentrations in the lung tissue, which were comparable to the medium range of the concentrations used for the in vitro chemotaxis assay.

We confirmed the observations from the model of LPSinduced pulmonary inflammation in a second model of acid-induced lung injury. Although the total numbers of neutrophils recruited to the alveolar compartment 2 hours after acid instillation were lower than 24 hours after LPS inhalation, the recruitment of neutrophils in this model leads to the development of acute lung injury and a compromised gas exchange [33].

\section{Conclusions}

In recent years, the mortality of ALI has been reduced by introducing new ventilation strategies [60], but there are no drugs available to effectively and specifically reduce neutrophil recruitment and vascular permeability to improve survival. The present data suggest that $12 / 15$ LO produced by hematopoietic cells is an important enzyme in regulating the accumulation of neutrophils in the interstitial and alveolar compartments. Therefore, blocking or eliminating 12/15-LO reduces neutrophil recruitment and could lead to a survival benefit in acute lung injury. We could show that inhibition of 12/15-LO by $C D C$ is effective as a pre-treatment. High doses of CDC are required to inhibit 12/15-LO [61-63], thus a more specific agent for the pharmacological blockade of 12/15-LO could be favorable as a possible new therapeutic approach in the treatment of ALI.

\section{Key messages}

- 12/15-LO is required for neutrophil recruitment into the lung during ALI

- 12/15-LO in hematopoietic cells is essential for neutrophil recruitment into the interstitial and alveolar compartment, whereas neutrophil recruitment into the intravascular compartment is regulated by $12 / 15-\mathrm{LO}$ in hematopoietic and nonhematopoietic cells

- Neutrophil recruitment is disturbed in 12/15-LOdeficient mice, possibly by alterations in the CXCL1/ CXCR2 chemokine axis

- Absence of 12/15-LO reduces survival in an acidinduced model of acute lung injury

\section{Abbreviations}

12/15-LO: 12/15-lipoxygenase; 12-HETE: 12-hydroxy-eicosatetraenoic acid; 12LO: 12-lipoxygenase; 15-HETE: 15-hydroxy-eicosatetraenoic acid; 15-LO: 15lipoxygenase; 5-HETE: 5-hydroxy-eicosatetraenoic acid; 5-LO: 5-lipoxygenase; ALI: acute lung injury; BAL: bronchoalveolar lavage; CDC: Cinnamyl-3,4Dihydroxy-a-Cyanocinnamate; CXCL1: keratinocyte-derived chemokine; CXCL2/3: macrophage inflammatory protein 2; CXCR2: C-X-C motif receptor 2; fMLP: n-formyl-methionine-leucine-phenylalanine; HCL: hydrochloric acid; IL-8: interleukin-8; LOX: lipoxygenase; LPS: lipopolysaccharide; LTB4: leukotriene B4; LXA4: lipoxin A4; PAK: p21-activated kinase; PBS: phosphate buffered saline; WT: wild-type.

\section{Acknowledgements}

This study was supported by grants from the German Research Foundation (AZ 428/3-1, AZ 428/6-1, AZ428/8-1 to A.Z.), Else Kröner-Fresenius-Stiftung (grant A69/07 to A.Z.), and Innovative Medizinische Forschung (IMF Münster, Germany, A.Z.). The funders had no role in study design, data collection and analysis, decision to publish or preparation of the manuscript.

\section{Author details}

'Department of Anesthesiology, Intensive Care and Pain Medicine, University of Münster, Albert-Schweitzer-Campus 1, Gebäude A1, Münster, 48149, Germany. ${ }^{2}$ Department of Internal Medicine, Eastern Virginia Medical School, P.O. Box 1980, Norfolk, VA 23501-1980, USA. ${ }^{3}$ Division of Inflammation Biology, La Jolla Institute for Allergy and Immunology, 9420 Athena Circle, La Jolla, CA 92037, USA.

\section{Authors' contributions}

JR performed experiments, helped analyze the data and wrote the manuscript. JN and KL helped design the study and revised the manuscript. AZ designed the study, performed experiments, analyzed the results and wrote the manuscript. All authors read and approved the final manuscript for publication.

\section{Competing interests}

The authors declare that they have no competing interests.

Received: 9 April 2012 Revised: 21 May 2012

Accepted: 13 September 2012 Published: 13 September 2012 


\section{References}

1. Rubenfeld GD, Caldwell E, Peabody E, Weaver J, Martin DP, Neff M, Stern EJ, Hudson LD: Incidence and outcomes of acute lung injury. N Engl J Med 2005, 353:1685-1693.

2. Ware LB, Matthay MA: The acute respiratory distress syndrome. $N$ Engl J Med 2000, 342:1334-1349.

3. Reutershan J, Basit A, Galkina EV, Ley K: Sequential recruitment of neutrophils into lung and bronchoalveolar lavage fluid in LPS-induced acute lung injury. Am J Physiol Lung Cell Mol Physiol 2005, 289:L807-815.

4. Doerschuk CM: Mechanisms of leukocyte sequestration in inflamed lungs. Microcirculation 2001, 8:71-88.

5. Reutershan J, Morris MA, Burcin TL, Smith DF, Chang D, Saprito MS, Ley K: Critical role of endothelial CXCR2 in LPS-induced neutrophil migration into the lung. J Clin Invest 2006, 116:695-702.

6. Belperio JA, Keane MP, Burdick MD, Londhe V, Xue YY, Li K, Phillips RJ, Strieter RM: Critical role for CXCR2 and CXCR2 ligands during the pathogenesis of ventilator-induced lung injury. J Clin Invest 2002, 110:1703-1716.

7. Zarbock A, Allegretti M, Ley K: Therapeutic inhibition of CXCR2 by Reparixin attenuates acute lung injury in mice. $\mathrm{Br} J$ Pharmacol 2008 , 155:357-364

8. Zeilhofer HU, Schorr W: Role of interleukin-8 in neutrophil signaling. Curr Opin Hematol 2000, 7:178-182.

9. Krupa A, Kato H, Matthay MA, Kurdowska AK: Proinflammatory activity of anti-IL-8 autoantibody:IL-8 complexes in alveolar edema fluid from patients with acute lung injury. Am J Physiol Lung Cell Mol Physiol 2004, 286:L1105-1113.

10. Frank JA, Matthay MA: Leukotrienes in acute lung injury: a potential therapeutic target? Am J Respir Crit Care Med 2005, 172:261-262.

11. Andersson CK, Claesson HE, Rydell-Tormanen K, Swedmark S, Hallgren A, Erjefalt JS: Mice lacking 12/15-lipoxygenase have attenuated airway allergic inflammation and remodeling. Am J Respir Cell Mol Biol 2008, 39:648-656.

12. Kuhn $H, \mathrm{O}^{\prime}$ Donnell VB: Inflammation and immune regulation by $12 / 15-$ lipoxygenases. Prog Lipid Res 2006, 45:334-356

13. Conrad DJ: The arachidonate 12/15 lipoxygenases. A review of tissue expression and biologic function. Clin Rev Allergy Immunol 1999, 17:71-89.

14. Belkner J, Stender H, Kuhn H: The rabbit 15-lipoxygenase preferentially oxygenates LDL cholesterol esters, and this reaction does not require vitamin E. J Biol Chem 1998, 273:23225-23232.

15. Kuhn $\mathrm{H}$, Belkner J, Suzuki H, Yamamoto S: Oxidative modification of human lipoproteins by lipoxygenases of different positional specificities. J Lipid Res 1994, 35:1749-1759.

16. Takahashi Y, Glasgow WC, Suzuki H, Taketani Y, Yamamoto S, Anton M, Kuhn $\mathrm{H}$, Brash AR: Investigation of the oxygenation of phospholipids by the porcine leukocyte and human platelet arachidonate 12lipoxygenases. Eur J Biochem 1993, 218:165-171.

17. Funk CD: The molecular biology of mammalian lipoxygenases and the quest for eicosanoid functions using lipoxygenase-deficient mice. Biochim Biophys Acta 1996, 1304:65-84.

18. Yoshimoto T, Takahashi Y: Arachidonate 12-lipoxygenases. Prostaglandins Other Lipid Mediat 2002, 68-69:245-262.

19. Khanapure SP, Garvey DS, Janero DR, Letts LG: Eicosanoids in inflammation: biosynthesis, pharmacology, and therapeutic frontiers. Curr Top Med Chem 2007, 7:311-340.

20. Chiang N, Serhan CN, Dahlen SE, Drazen JM, Hay DW, Rovati GE, Shimizu T, Yokomizo T, Brink C: The lipoxin receptor ALX: potent ligand-specific and stereoselective actions in vivo. Pharmacol Rev 2006, 58:463-487.

21. Huo $Y$, Zhao L, Hyman MC, Shashkin P, Harry BL, Burcin T, Forlow SB, Stark MA, Smith DF, Clarke S, Srinivasan S, Hedrick CC, Praticò D, Witztum JL, Nadler JL, Funk CD, Ley K: Critical role of macrophage 12/15lipoxygenase for atherosclerosis in apolipoprotein E-deficient mice. Circulation 2004, 110:2024-2031.

22. Hatley ME, Srinivasan S, Reilly KB, Bolick DT, Hedrick CC: Increased production of 12/15 lipoxygenase eicosanoids accelerates monocyte/ endothelial interactions in diabetic db/db mice. J Biol Chem 2003, 278:25369-25375.

23. Cunningham FM, Woollard PM: 12(R)-hydroxy-5,8,10,14-eicosatetraenoic acid is a chemoattractant for human polymorphonuclear leucocytes in vitro. Prostaglandins 1987, 34:71-78.
24. Tang DG, Timar J, Grossi IM, Renaud C, Kimler VA, Diglio CA, Taylor JD, Honn KV: The lipoxygenase metabolite, 12(S)-HETE, induces a protein kinase C-dependent cytoskeletal rearrangement and retraction of microvascular endothelial cells. Exp Cell Res 1993, 207:361-375.

25. Wen Y, Gu J, Chakrabarti SK, Aylor K, Marshall J, Takahashi Y, Yoshimoto T, Nadler JL: The role of 12/15-lipoxygenase in the expression of interleukin-6 and tumor necrosis factor-alpha in macrophages. Endocrinology 2007, 148:1313-1322.

26. Bolick DT, Orr AW, Whetzel A, Srinivasan S, Hatley ME, Schwartz MA, Hedrick CC: 12/15-lipoxygenase regulates intercellular adhesion molecule-1 expression and monocyte adhesion to endothelium through activation of RhoA and nuclear factor-kappaB. Arterioscler Thromb Vasc Biol 2005, 25:2301-2307.

27. Hajek AR, Lindley AR, Favoreto S Jr, Carter R, Schleimer RP, Kuperman DA: 12/15-Lipoxygenase deficiency protects mice from allergic airways inflammation and increases secretory IgA levels. J Allergy Clin Immunol 2008, 122:633-639.

28. Shen J, Herderick E, Cornhill JF, Zsigmond E, Kim HS, Kuhn H, Guevara NV, Chan L: Macrophage-mediated 15-lipoxygenase expression protects against atherosclerosis development. J Clin Invest 1996, 98:2201-2208.

29. Serhan CN, Jain A, Marleau S, Clish C, Kantarci A, Behbehani B, Colgan SP, Stahl GL, Merched A, Petasis NA, Chan L, Van Dyke TE: Reduced inflammation and tissue damage in transgenic rabbits overexpressing 15-lipoxygenase and endogenous anti-inflammatory lipid mediators. J Immunol 2003, 171:6856-6865.

30. Caironi P, Ichinose F, Liu R, Jones RC, Bloch KD, Zapol WM: 5-Lipoxygenase deficiency prevents respiratory failure during ventilator-induced lung injury. Am J Respir Crit Care Med 2005, 172:334-343.

31. Zarbock A, Distasi MR, Smith E, Sanders JM, Kronke G, Harry BL, von Vietinghoff S, Buscher K, Nadler JL, Ley K: Improved survival and reduced vascular permeability by eliminating or blocking 12/15-lipoxygenase in mouse models of acute lung injury (ALI). J Immunol 2009, 183:4715-4722.

32. Funk $C D$, Chen $X S$, Johnson EN, Zhao L: Lipoxygenase genes and their targeted disruption. Prostaglandins Other Lipid Mediat 2002, 68-69:303-312.

33. Zarbock A, Singbartl K, Ley K: Complete reversal of acid-induced acute lung injury by blocking of platelet-neutrophil aggregation. J Clin Invest 2006, 116:3211-3219.

34. Zarbock A, Schmolke M, Spieker T, Jurk K, Van Aken H, Singbartl K: Acute uremia but not renal inflammation attenuates aseptic acute lung injury: a critical role for uremic neutrophils. J Am Soc Nephrol 2006, 17:3124-3131.

35. Singbartl K, Bockhorn SG, Zarbock A, Schmolke M, Van Aken H: T cells modulate neutrophil-dependent acute renal failure during endotoxemia: critical role for CD28. J Am Soc Nephrol 2005, 16:720-728.

36. Ma J, Natarajan R, LaPage J, Lanting L, Kim N, Becerra D, Clemmons B, Nast CC, Surya Prakash GK, Mandal M, Adler SG: 12/15-lipoxygenase inhibitors in diabetic nephropathy in the rat. Prostaglandins Leukot Essent Fatty Acids 2005, 72:13-20.

37. Strieter RM, Keane MP, Burdick MD, Sakkour A, Murray LA, Belperio JA: The role of CXCR2/CXCR2 ligands in acute lung injury. Curr Drug Targets Inflamm Allergy 2005, 4:299-303.

38. Tsai WC, Strieter RM, Mehrad B, Newstead MW, Zeng X, Standiford TJ: CXC chemokine receptor CXCR2 is essential for protective innate host response in murine Pseudomonas aeruginosa pneumonia. Infect Immun 2000, 68:4289-4296.

39. Kronke G, Katzenbeisser J, Uderhardt S, Zaiss MM, Scholtysek C, Schabbauer G, Zarbock A, Koenders MI, Axmann R, Zwerina J, Baenckler HW, van den Berg W, Voll RE, Kühn H, Joosten LA, Schett G: 12/ 15-lipoxygenase counteracts inflammation and tissue damage in arthritis. J Immunol 2009, 183:3383-3389.

40. George J, Afek A, Shaish A, Levkovitz H, Bloom N, Cyrus T, Zhao L, Funk CD, Sigal $E$, Harats D: 12/15-Lipoxygenase gene disruption attenuates atherogenesis in LDL receptor-deficient mice. Circulation 2001, 104:1646-1650

41. Cyrus T, Witztum JL, Rader DJ, Tangirala R, Fazio S, Linton MF, Funk CD: Disruption of the 12/15-lipoxygenase gene diminishes atherosclerosis in apo E-deficient mice. J Clin Invest 1999, 103:1597-1604.

42. Bleich D, Chen S, Zipser B, Sun D, Funk CD, Nadler JL: Resistance to type 1 diabetes induction in 12-lipoxygenase knockout mice. J Clin Invest 1999, 103:1431-1436. 
43. Brigham KL: Pulmonary dysfunction caused by diffuse lung inflammation. Roles of metabolites of arachidonic acid. Prog Biochem Pharmacol 1985, 20:26-37.

44. Cornicelli JA, Trivedi BK: 15-Lipoxygenase and its inhibition: a novel therapeutic target for vascular disease. Curr Pharm Des 1999, 5:11-20.

45. Dailey LA, Imming P: 12-Lipoxygenase: classification, possible therapeutic benefits from inhibition, and inhibitors. Curr Med Chem 1999, 6:389-398.

46. Basit A, Reutershan J, Morris MA, Solga M, Rose CE Jr, Ley K: ICAM-1 and LFA-1 play critical roles in LPS-induced neutrophil recruitment into the alveolar space. Am J Physiol Lung Cell Mol Physiol 2006, 291:L200-207.

47. Hedrick CC, Kim MD, Natarajan RD, Nadler JL: 12-Lipoxygenase products increase monocyte:endothelial interactions. Adv Exp Med Biol 1999, 469:455-460

48. Pero RS, Borchers MT, Spicher K, Ochkur SI, Sikora L, Rao SP, AbdalaValencia H, O'Neill KR, Shen H, McGarry MP, Lee NA, Cook-Mills JM, Sriramarao P, Simon Ml, Birnbaumer L, Lee JJ: Galphai2-mediated signaling events in the endothelium are involved in controlling leukocyte extravasation. Proc Natl Acad Sci USA 2007, 104:4371-4376.

49. Guo Y, Zhang W, Giroux C, Cai Y, Ekambaram P, Dilly AK, Hsu A, Zhou S, Maddipati KR, Liu J, Joshi S, Tucker SC, Lee MJ, Honn KV: Identification of the orphan G protein-coupled receptor GPR31 as a receptor for 12-(S)hydroxyeicosatetraenoic acid. J Biol Chem 2011, 286:33832-33840.

50. Wen Y, Gu J, Knaus UG, Thomas L, Gonzales N, Nadler JL: Evidence that 12-lipoxygenase product 12-hydroxyeicosatetraenoic acid activates p21activated kinase. Biochem J 2000, 349:481-487.

51. Natarajan R, Yang DC, Lanting L, Nadler JL: Key role of P38 mitogenactivated protein kinase and the lipoxygenase pathway in angiotensin II actions in H295R adrenocortical cells. Endocrine 2002, 18:295-301.

52. Reutershan J, Stockton R, Zarbock A, Sullivan GW, Chang D, Scott D, Schwartz MA, Ley K: Blocking p21-activated kinase reduces lipopolysaccharide-induced acute lung injury by preventing polymorphonuclear leukocyte infiltration. Am J Respir Crit Care Med 2007, 175:1027-1035.

53. Kuhn $\mathrm{H}$, Chan $\mathrm{L}$ : The role of 15-lipoxygenase in atherogenesis: pro- and antiatherogenic actions. Curr Opin Lipidol 1997, 8:111-117.

54. Merched AJ, Ko K, Gotlinger KH, Serhan CN, Chan L: Atherosclerosis: evidence for impairment of resolution of vascular inflammation governed by specific lipid mediators. FASEB J 2008, 22:3595-3606.

55. Serhan CN: Lipoxins and novel aspirin-triggered 15-epi-lipoxins (ATL): a jungle of cell-cell interactions or a therapeutic opportunity? Prostaglandins 1997, 53:107-137.

56. Takata S, Matsubara M, Allen PG, Janmey PA, Serhan CN, Brady HR: Remodeling of neutrophil phospholipids with 15(S)hydroxyeicosatetraenoic acid inhibits leukotriene B4-induced neutrophil migration across endothelium. J Clin Invest 1994, 93:499-508.

57. Brezinski ME, Serhan CN: Selective incorporation of (15S)hydroxyeicosatetraenoic acid in phosphatidylinositol of human neutrophils: agonist-induced deacylation and transformation of stored hydroxyeicosanoids. Proc Natl Acad Sci USA 1990, 87:6248-6252.

58. Legrand AB, Lawson JA, Meyrick BO, Blair IA, Oates JA: Substitution of 15hydroxyeicosatetraenoic acid in the phosphoinositide signaling pathway. J Biol Chem 1991, 266:7570-7577.

59. Decker Y, McBean G, Godson C: Lipoxin A4 inhibits IL-1beta-induced IL-8 and ICAM-1 expression in 1321N1 human astrocytoma cells. Am J Physiol Cell Physiol 2009, 296:C1420-1427.

60. Ventilation with lower tidal volumes as compared with traditional tidal volumes for acute lung injury and the acute respiratory distress syndrome. The Acute Respiratory Distress Syndrome Network. N Engl J Med 2000, 342:1301-1308.

61. Zhou W, Wang XL, Kaduce TL, Spector AA, Lee HC: Impaired arachidonic acid-mediated dilation of small mesenteric arteries in Zucker diabetic fatty rats. Am J Physiol Heart Circ Physiol 2005, 288:H2210-2218.

62. Ye H, Bi HR, Lu CL, Tang XB, Zhu DL: 15-hydroxyeicosatetraenoic acid depressed endothelial nitric oxide synthase activity in pulmonary artery. Sheng Li Xue Bao 2005, 57:612-618.

63. Lu C, Liu Y, Tang X, Ye H, Zhu D: Role of 15-hydroxyeicosatetraenoic acid in phosphorylation of ERK $1 / 2$ and caldesmon in pulmonary arterial smooth muscle cells. Can J Physiol Pharmacol 2006, 84:1061-1069. doi:10.1186/cc11518

Cite this article as: Rossaint et al:: Eliminating or blocking 12/15-

lipoxygenase reduces neutrophil recruitment in mouse models of acute lung injury. Critical Care 2012 16:R166.

\section{Submit your next manuscript to BioMed Central and take full advantage of:}

- Convenient online submission

- Thorough peer review

- No space constraints or color figure charges

- Immediate publication on acceptance

- Inclusion in PubMed, CAS, Scopus and Google Scholar

- Research which is freely available for redistribution 